\title{
Segmentation Based On Media Consumption: A Better Way To Plan Integrated Marketing Communications Media
}

Kurt Schimmel, (E-mail: schimmel@rmu.edu), Robert Morris University Jeananne Nicholls, Strategic planning and technology consultant

\begin{abstract}
This paper provides an example of utilizing survey data to develop the initial media and method (Advertising, PR, Interactive, Word of mouth) mix. Utilizing K-Means Cluster analysis and discriminant analysis to profile the clusters three segments were identified based on media consumption. Differences in the segments were also found to exist regarding the perceptions of the benefits and concerns regarding e-commerce. This indicated that in addition to different media/method mixes, different message strategies are also appropriate for the segments. The segments were then profiled utilizing Multiple Correspondence Analysis to determine the relationship between the segments and the demographic variables and also between the segments and shopping behavior
\end{abstract}

\section{INTRODUCTION}

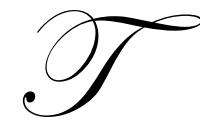

he concept that synergistically utilizing a media mix of advertising, public relations, interactive communications and word of mouth (WOM) to maximize the impact of a marketing communications campaign to reach consumers with the right message, in the right media, is intuitively logical and accepted by both academics and practitioners. Integrating media increases synergies in delivering messages as demonstrated by Naik and Raman (2003). The need to develop better media planning methods that maximize synergy and increase efficiencies while decreasing overspending has been noted in recent literature ( Hoeffler 2003; Schultz 2002). This article addresses this need. It presents an exploratory study that presents a consumer centric method for developing media plans.

No research exists addressing how this mix should be developed. What is the optimal communications method mix to reach the e-commerce consumer? How should that mix be determined? These are two key questions facing marketing managers and advertisers for e-tailers. If the right message is placed in the wrong media, or if the message is conveyed through the wrong method, it will miss the target audience wasting the marketing communications budget.

While there is a body of research that examines differing methods to compare advertising media (Woodside and Soni, 1990; Woodside, 1994) and theoretical work on how to utilize the communications methods synergistically (Bond \& Kirshenbaum, 1998; Ephron, 2000), there is no work that proposes how to determine the appropriate mix across message delivery formats (Advertising, Public Relations etc.).

This paper demonstrates how the common database marketing technique of behavioral-based, post-hoc market segmentation is applied to media consumption and guides the integrated marketing communications planner. Segmentation based on media use has the benefit of allowing a greater degree of message targeting with customized 
messages being developed for each segment. It also allows for more efficient message delivery targeting the specific niches.

\section{“TRADITIONAL” MEDIA MIX METHODS}

The traditional model of media planning taught in text books (for examples see Donnelly 1996, Rossiter and Percy 1997, Sissors and Bumba 1995, Taylor 1993) addresses advertising media purchases and does not address the selection of method delivery for the messages. The focus is on utilizing the ARF model's stages to evaluate media. These stages are: vehicle distribution; vehicle exposure, advertising exposure, advertising perception, advertising communication and sales response. This model has been expanded for interactive web media and includes vehicle distribution, vehicle exposure, advertising exposure, persuasion, leads, sales, profits, customer loyalty, and finally return on investment (Harvey, 1997). The practical result of this model results in translating consumer demographic profiles and measures such as reach \& frequency (Leckneby and Hong, 1998), exposure (Abe, 1997), effective frequency (Broadbent, Spittler and Lynch, 1997), cost per thousand impressions (Lloyd and Clancy, 1991), and gross rating points (Masterson, 1999) to develop an advertising based media mix only.

Another stream of media planning research that has developed since the introduction of IMC is increasing the emphasis on "impact" measures as a method for evaluating media. Schultz, Tannenbaum and Lauterborn (1993) emphasizes return on investment (ROI) as the key measure behind an IMC campaign. Woodside and Soni (1990) and Woodside (1994), develop a performance grid based on cost per inquiry (CPI) and revenue per inquiry (RPI). These measures provide a guide for future media purchases and are used to evaluate message delivery methods after the media plan is implemented. However, they do not provide a guide for the initial IMC media/method delivery plan.

Additionally, research has experimentally examined the impact of specific media on consumer decision processes (Bruner and Kumar, 2000; Gibson, 1996; Puth, Mostert and Ewing, 1999). These results indicate that the impact of each media changes with each product category since consumer information searches differ across product categories.

\section{THE PROBLEM}

None of the previously cited research guides tactical utilization and planning across message delivery methods. That is they do not answer questions such as: when is PR better? When should there be a focus on interactive advertising? How will the communications methods work together, compliment each other tactically, and how do these decisions get made? These are the real decisions to be faced prior to developing an IMC campaign that have, to date, been unanswered by academic research.

Additionally none of the prior research has utilized the consumer's media consumption habits. They have used demographic and psychographic profiles of the consumer then matched the media, messages and the methods based on these broad characteristics. However, none of the methods have queried customers as to their media consumption habits.

\section{PROPOSED SOLUTION}

The concept of segmentation for media planning itself is not new. Recent studies in media planning have uses segments based on demographic characteristics (Davis and French 1989; Korgaonkar, Silverblatt and O'Leary 2001), media consumption patterns for advertising (Kim, 2002), attitudes toward advertising (Bond and Brace 1997; Smith \& Neijens 2000), and product consumption (Wansink and Park, 2000) to name a few recent studies.

Post hoc segmentation methods are also common within e-commerce to examine flow patterns, shopping behavior, and web visitation among other techniques. This paper suggests that segmentation based on media consumption should be utilized to develop the initial message delivery mix in an IMC campaign. After the initial campaign is started, the application of the Media Vehicle Performance grid (Woodside and Soni, 1990) can be applied to explore the impact of the communication methods suggested for revising and refining the media plan. 
The approach we propose applies the tenets of IMC and focuses on understanding the consumer while providing information in a synergistic manner to maximize the impact and limit the costs. The first step is to understand the consumer. As part of the initial business plan, research was conducted to determine the viability of the niche as a target market. Within this initial research, customers were queried to determine what media vehicles (TV, Newspapers, Radio, Web-based) they consumed for shopping information. The survey also explored which methods (such as advertising, PR, interactive) had the greatest impact in influencing consumers to shop on-line. Finally the consumers were asked what were their underlying motivations for shopping online. This data provides the basis for the initial IMC plan. It identified the media this stores consumers utilize, what methods have the greatest influence and what message should be sent for the greatest impact. The key idea is that if there are underlying segments that consume media differently, a media plan that does not address these segments through targeted communications will place the communications in the wrong media or deliver the wrong message in media. Either of these outcomes results in wasted promotional budget and resources.

\section{THE COMPANY}

The research for the media plan was undertaken for a new niche marketed e-catalog. The organization had a limited marketing communications budget and needed to "get it right the first time." Of primary concern was reaching the consumer with the correct information using the correct media to maximize the return on the marketing communications investment.

\section{SURVEY METHODOLOGY}

The data was collected by a phone survey of 308 respondents in seven cities. These cities were chosen for the proportionally greater percentage of on-line consumers compared to other regions in the country. The data was collected over a three day period using a phone bank of professional interviewers and a computer assisted telephone interviewing system (CATI), which automatically coded the responses into a database.

Data regarding media consumption was collected using a four point semantic differential scale anchored by "frequently" and "never". Respondents were asked, "How often to the following encourage you to search for products on a particular Internet website?" The following, Table One presents a list of message methods (PR, WOM, Internet) and the specific media (television, radio, magazine newspaper) along with the methods.

Table One

Media and Methods Examined in Survey

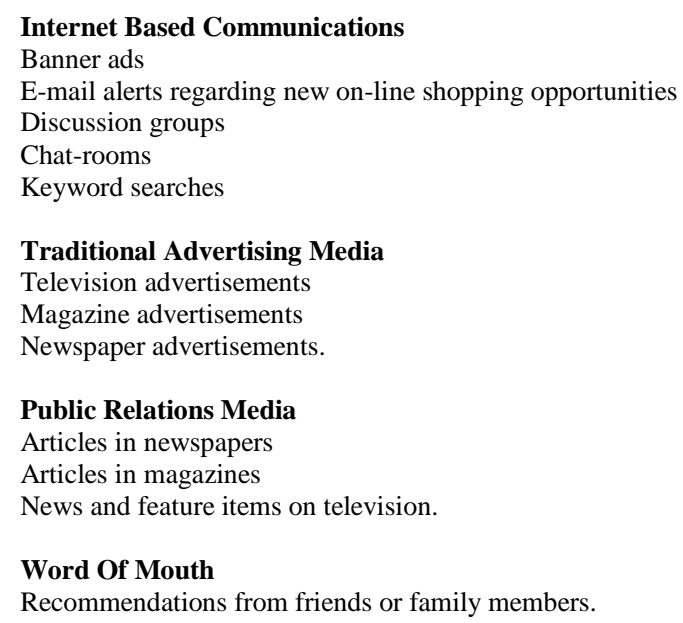

The data exploring the perceptions of the benefits and concerns regarding Internet shopping were collected as follows: concerns were assessed on a fourpoint scale anchored by one "A lot" and four "Not at all." These questions addressed the consumer's degree of concern. (How concerned are you about return policies when shopping on-line?) The benefits and attributes were assessed on a five point scale anchored by one "very important" and five "not at all important." They examined the importance of the attributes to the consumer. (Example: How important is seeing a picture of an item before you purchase it?)

\section{METHODOLOGY}

The purpose of the study is to demonstrate a methodology to develop an "ideal" marketing communications mix. The idea was that there are underlying 
segments based on media consumption. To identify these segments cluster analysis was performed on the data collected regarding the consumers consumption of media. K-means cluster analysis since the data was interval level (Chaturvedi, Carroll,Green \& Rotondo ,1997). Through an iterative process that sought to identify a managerially useful cluster solution while minimizing the iteration history a three cluster solution was determined to be best. Univariate anova's were examined and mean differences were found among the segments. To further demonstrate the validity of the segments discriminant analysis was conducted to profile the segments and determine if the segments were unique enough to develop classificatory functions.

In order to profile the segments Multiple Correspondence Analysis using Homals in SPSS was conducted. MCA allows the joint representation of contingency table data in perceptual space. It therefore provides an easily interpreted perceptual map that jointly shows the relationship between the categorical variables not available through the traditional method of using Chi-Squares on a bi-variate level of analysis. (Hair, Anderson Tatham and Black 1998; Javalgi Whipple and McManamon, 1992)

Then to test whether differences existed among the segments regarding message content, the primary benefits and concerns about online shopping were examined using discriminant analysis. This allows for the examination of the differences at the variable level (the univariate $\mathrm{F}$ tests) and as a group (the wilkes lambda for the function). The following are the results.

\section{RESULTS}

\section{Demographics}

As Table Two indicates, the respondents mirror the e-commerce literature regarding the profile of the consumer. They tend to be younger with over 50 percent between 25 and 44; better educated, 58 percent were college graduates and/or had post graduate education; with a better income, 55 percent reported a household income of at least $\$ 50,000$ dollars. The sample diverged from the literature in that there is a 50/50 split based on gender. This 50/50 split was done purposefully at the client's request. Table Two details the demographic profile of the respondents.

Table Two

Demographics of Respondents

\begin{tabular}{|c|c|c|c|c|c|}
\hline Age & \# & $\%$ & Gender & \# & $\%$ \\
\hline $18-24$ & 29 & $9 \%$ & Male & 154 & $50 \%$ \\
\hline $25-34$ & 82 & $27 \%$ & Female & 154 & $50 \%$ \\
\hline $35-44$ & 90 & $39 \%$ & & & \\
\hline $45-54$ & 71 & $23 \%$ & & & \\
\hline $55-64$ & 27 & $9 \%$ & & & \\
\hline 65 up & 5 & $2 \%$ & & & \\
\hline $\mathrm{Na}$ & 4 & $1 \%$ & & & \\
\hline \multicolumn{6}{|c|}{ Education } \\
\hline \multicolumn{4}{|c|}{ Highest level attained } & $\#$ & $\%$ \\
\hline \multicolumn{4}{|c|}{ Less than high School } & 4 & $1 \%$ \\
\hline \multicolumn{4}{|c|}{ High School Graduate } & 50 & $16 \%$ \\
\hline \multicolumn{4}{|c|}{ Some College/Technical School } & 71 & $23 \%$ \\
\hline \multicolumn{4}{|c|}{ College Graduate/Post Graduate } & 178 & $58 \%$ \\
\hline \multicolumn{4}{|l|}{$\mathrm{Na}$} & 5 & $2 \%$ \\
\hline \multicolumn{6}{|c|}{ Income } \\
\hline \multicolumn{4}{|c|}{ Under $\$ 30,000$} & 24 & $8 \%$ \\
\hline \multicolumn{4}{|c|}{$\$ 30,000-\$ 50,000$} & 68 & $22 \%$ \\
\hline \multicolumn{4}{|c|}{$\$ 50,000-\$ 100,000$} & 107 & $35 \%$ \\
\hline \multicolumn{4}{|c|}{ Over $\$ 100,000$} & 60 & $20 \%$ \\
\hline \multicolumn{4}{|c|}{$\mathrm{Dk} / \mathrm{Na} / \mathrm{Rf}$} & 49 & $16 \%$ \\
\hline
\end{tabular}

\section{Computer Usage}

Ninety-three percent of e-commerce consumers have access to the Internet at home, of which 25 percent have access at home only and 58 percent have access at both home and work.

Eighty three percent of the respondents identify themselves as either frequent or occasional purchasers of products or services on-line. The nine percent that indicate they never purchase products or services had previously identified themselves as on-line consumers. These respondents may subscribe to websites or web-based information systems (services were not defined and this may have led to the confusion).

While the majority, 80 percent, of the respondents placed less than 20 orders within the past year, 47 percent of the respondents spent over $\$ 500$ dollars in that same period of time. Christmas and birthdays were the occasions for which consumers noted they most frequently shopped on-line. Data detailing respondents computer usage and buying habits is depicted in Table Three. 
Table Three

E-commerce Access and Behavior

\begin{tabular}{lll} 
Respondents have access to the internet at... \\
\cline { 2 - 3 } \\
Home & 107 & $\%$ \\
Work & 22 & $35 \%$ \\
Both & 179 & $58 \%$ \\
None & 0 & 0
\end{tabular}

How many orders have you placed on-line in the past year?

\begin{tabular}{lll} 
& \multicolumn{2}{c}{$\%$} \\
\cline { 2 - 3 } Less than 10 & 105 & $47 \%$ \\
$11-20$ & 73 & $33 \%$ \\
$21-50$ & 27 & $12 \%$ \\
Over 50 & 19 & $8 \%$
\end{tabular}

How much money have you spent in on-line purchases?

Less than $\$ 100$

$\$ 101-\$ 500$

$\$ 501-\$ 1000$

over $\$ 1000$

\begin{tabular}{ll} 
& $\%$ \\
\hline 27 & $12 \%$ \\
91 & $41 \%$ \\
45 & $20 \%$ \\
60 & $27 \%$
\end{tabular}

*Note there were 224 respondents who answered the questions presented in table two.
K-Means cluster analysis was conducted on the media consumption variables to determine if there were underlying segments that could be efficiently targeted with the media plan. This approach has been noted as appropriate for market segmentation (Chaturvedi, Carroll, Green and Rotondo, 1997; Schaffer and Green, 1998). A three cluster solution was chosen because it had cluster memberships that divided the sample into approximately thirds that were internally homogeneous and externally heterogeneous. The clusters were then validated using multiple discriminant analysis. Tables Four through Six provide the results of the cluster analysis and the validation of the clusters.

\section{Cluster Analysis Results}

Table Four presents the results of the k-means cluster analysis. The three cluster solution has 144 members in the first group, 83 members in the second group and 81 members of the third. Convergence was achieved at the $13^{\text {th }}$ iteration with a minimum distance between the initial cluster centers of 8.367. This fulfills the criteria for a managerially useful solution (Hair et al. 1998). There are three segments each representing approximately $1 / 3$ of the respondents and which are also distinct in their media consumption.
Prior Probabilities for Groups

\begin{tabular}{|l|r|r|r|}
\hline \multirow{2}{*}{ Cluster Number of Case } & & \multicolumn{2}{|c|}{ Cases Used in Analy sis } \\
\cline { 3 - 4 } & \multicolumn{1}{|c|}{ Prior } & Unweighted & Weighted \\
\hline 1 & .468 & 144 & 144.000 \\
2 & .269 & 83 & 83.000 \\
3 & .263 & 81 & 81.000 \\
Total & 1.000 & 308 & 308.000 \\
\hline
\end{tabular}

Table Four

Results of K means Cluster Analysis

\begin{tabular}{|lccc|}
\hline Variable & Final & Cluster & Centers \\
& & & \\
Recommendations & 1.77 & 1.67 & 2.65 \\
Banner Ads & 3.02 & 2.93 & 3.80 \\
Articles in Magazines 2.60 & 1.74 & 3.05 & \\
Articles in Newspapers & 3.50 & 1.88 & 3.27 \\
Television Ads & 2.46 & 2.06 & 3.63 \\
Newspaper Ads & 3.52 & 2.01 & 3.60 \\
Magazine Ads & 2.65 & 1.92 & 3.24 \\
Chat-rooms & 3.73 & 3.60 & 4.00 \\
Keyword Search & 1.83 & 2.51 & 3.16 \\
News Items on TV & 2.41 & 2.04 & 3.51 \\
E-mail Ads & 2.73 & 2.88 & 3.70 \\
Discussion Groups & 3.65 & 3.42 & 3.84 \\
& & & \\
\hline
\end{tabular}


Iteration History

\begin{tabular}{|l|r|r|r|}
\hline \multirow{2}{*}{ Iteration } & \multicolumn{3}{|c|}{ Change in Cluster Centers } \\
\cline { 2 - 4 } & \multicolumn{1}{|c|}{1} & \multicolumn{1}{|c|}{2} & \multicolumn{1}{c|}{3} \\
\hline 1 & 4.282 & 4.168 & 4.645 \\
3 & .280 & .290 & .445 \\
4 & .134 & $6.555 \mathrm{E}-02$ & .241 \\
5 & .107 & $2.989 \mathrm{E}-02$ & .143 \\
6 & $6.128 \mathrm{E}-02$ & $2.294 \mathrm{E}-02$ & $4.706 \mathrm{E}-02$ \\
7 & $7.566 \mathrm{E}-02$ & $2.219 \mathrm{E}-02$ & $6.039 \mathrm{E}-02$ \\
8 & $7.154 \mathrm{E}-02$ & $4.404 \mathrm{E}-02$ & .000 \\
9 & $9.856 \mathrm{E}-02$ & $2.488 \mathrm{E}-02$ & $8.324 \mathrm{E}-02$ \\
10 & .105 & $2.906 \mathrm{E}-02$ & $7.341 \mathrm{E}-02$ \\
11 & $4.948 \mathrm{E}-02$ & .000 & $5.082 \mathrm{E}-02$ \\
12 & $3.538 \mathrm{E}-02$ & $4.213 \mathrm{E}-02$ & $9.923 \mathrm{E}-02$ \\
13 & $4.322 \mathrm{E}-02$ & .000 & $4.199 \mathrm{E}-02$ \\
& .000 & .000 & .000 \\
\hline
\end{tabular}

a. Convergence achieved due to no or small distance change. The maximum distance by which any center has changed is .000 . The current iteration is 13 . The minimum distance between initial centers is 8.367 .

Table Five

Discriminant Analysis Validation of Cluster Results

\begin{tabular}{|llllll}
\hline \multicolumn{2}{l}{ Tests of Equality of Group Means } & & & & \\
& $\begin{array}{l}\text { Wilkes } \\
\text { Lambda }\end{array}$ & F & df1 & df2 & Sig. \\
& & & & & \\
Recommendations & .808 & 36.35 & 2 & 305 & .000 \\
Banner Ads & .849 & 27.06 & 2 & 305 & .000 \\
Articles in Magazines & .688 & 69.28 & 2 & 305 & .000 \\
Articles in Newspapers & .517 & 142.73 & 2 & 305 & .000 \\
Television Ads & .602 & 100.88 & 2 & 305 & .000 \\
Newspaper Ads & .429 & 202.65 & 2 & 305 & .000 \\
Magazine Ads & .710 & 62.21 & 2 & 305 & .000 \\
Chat-rooms & .936 & 10.69 & 2 & 305 & .000 \\
Keyword Search & .853 & 26.25 & 2 & 305 & .000 \\
News Items on TV & .685 & 20.22 & 2 & 305 & .000 \\
E-mail Ads & .852 & 26.44 & 2 & 305 & .000 \\
Discussion Groups & .948 & 8.34 & 2 & 305 & .000 \\
\end{tabular}

In Table Five, the results of the discriminant analysis validating the segments are presented. The results indicate two highly significant discriminant functions with a Wilk's lambda of .167 for the first function and a Wilk's lambda of .584 for the second and both functions are significant at the $\mathrm{P}<.000$ level. The tests for the equality of group means resulted in significant differences at the $\mathrm{P}<.000$ level for all media consumption variables, indicating that there are significant differences between the group means on every variable.

An examination of the validation measures in Table Six reveals that the discriminant functions successfully classify $92.9 \%$ in the cross functional classification of grouped cases, which is a predictive validity for the discriminant function that is much better than chance. 
These results indicate that there are three separate segments based on media consumption, which are internally homogeneous and externally heterogeneous. Descriptions of the three clusters follow, with mean values presented in parenthesis.

Eigenvalues
\begin{tabular}{|l|r|r|r|r|}
\hline Function & Eigenvalue & $\%$ of Variance & Cumulative \% & $\begin{array}{c}\text { Canonical } \\
\text { Correlation }\end{array}$ \\
\hline 1 & $2.506^{\mathrm{a}}$ & 77.9 & 77.9 & .845 \\
2 & $.712^{\mathrm{a}}$ & 22.1 & 100.0 & .645 \\
\hline
\end{tabular}

a. First 2 canonical discriminant functions were used in the analysis.

Wilks' Lambda

\begin{tabular}{|l|r|r|r|r|}
\hline Test of Function(s) & $\begin{array}{c}\text { Wilks' } \\
\text { Lambda }\end{array}$ & Chi-square & \multicolumn{1}{c|}{ df } & \multicolumn{1}{c|}{ Sig. } \\
\hline 1 through 2 & .167 & 536.724 & 24 & .000 \\
2 & .584 & 161.011 & 11 & .000 \\
\hline
\end{tabular}

Table Six

Prior Probabilities for Groups

\begin{tabular}{|l|r|r|r|}
\hline \multirow{2}{*}{ Cluster Number of Case } & & \multicolumn{2}{|c|}{ Cases Used in Analy sis } \\
\cline { 3 - 4 } & \multicolumn{1}{|c|}{ Prior } & Unweighted & Weighted \\
\hline 1 & .468 & 144 & 144.000 \\
2 & .269 & 83 & 83.000 \\
3 & .263 & 81 & 81.000 \\
Total & 1.000 & 308 & 308.000 \\
\hline
\end{tabular}

Classification Results,c

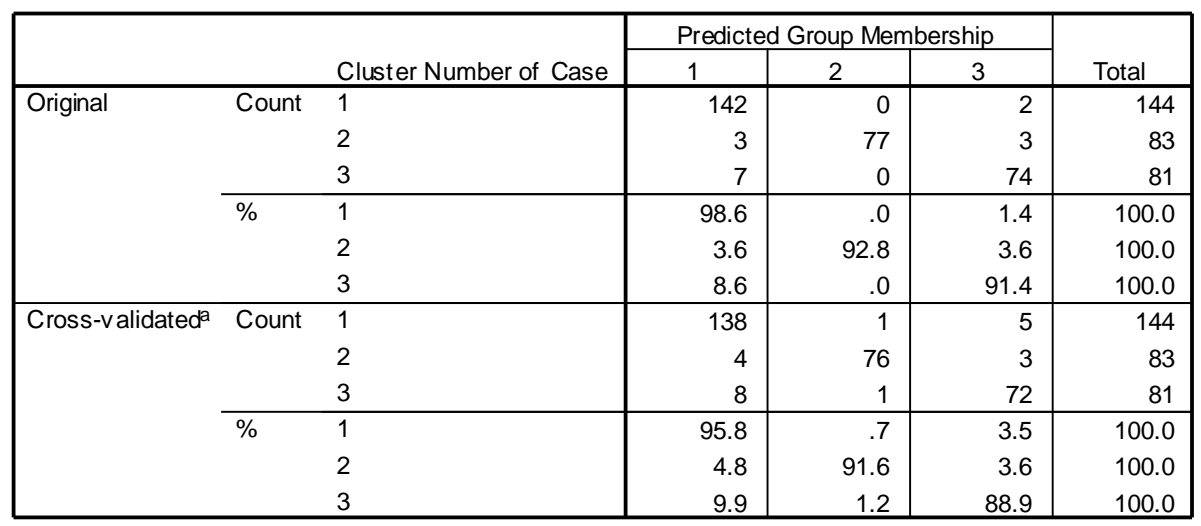

a. Cross validation is done only for those cases in the analy sis. In cross validation, each case is classif ied by the functions derived from all cases other than that case.

b. $95.1 \%$ of original grouped cases correctly classif ied.

c. $92.9 \%$ of cross-validated grouped cases correctly classified. 


\section{CLUSTER PROFILES}

Cluster One: There were 144 members of Cluster One, which represents 47 percent of the sample. The information sources that encourage this group to shop for products on a web site were: Recommendation of friends and family (1.77) followed by keyword searches (1.82) these were frequent to occasional sources of information. News items or features on television (2.41) and television ads (2.46) were occasional sources of information. Magazine articles (2.60), magazine ads (2.65) and e-mail alerts regarding new on-line opportunities (2.73) were situated between occasionally and rarely (leaning more toward rarely) encourage on-line shopping. Banner ads (3.02) rarely encourage on-line shopping, while articles in newspapers (3.50), newspaper ads (3.52), discussion groups (3.65) and chat-rooms (3.73) rarely to never encourage on-line shopping.

Cluster Two: With 82 members representing 27 percent of the sample, Cluster Two was the most persuaded by the media. For Cluster Two the information sources that encourage shopping for products on the web were: Recommendations of friends and family (1.67), followed by articles in magazines (1.74) and were both used between frequently and occasionally. Articles in newspapers (1.88), magazine ads (1.92), newspaper ads (2.01), news items or features on television (2.04), and finally television ads (2.06) all occasionally encourage this segment to shop on the internet. The Internet based media were the least used by this segment and included keyword searches (2.51), e-mail alerts regarding new on-line opportunities (2.88), and banner ads (2.93) all rarely encouraging shopping. Finally, discussion groups (3.42) and chat-rooms rarely to never encouraged shopping.

Cluster Three: This group was the least encouraged to shop on-line by any of the media. There were 81 members representing $26 \%$ of the sample. None of the media had a response of less than 2.65 on the four point scale. Recommendations by friends and family (2.65) occasionally to rarely impacted their on-line shopping. Articles in magazines (3.05), keyword searches (3.16), magazine ads (3.24), and articles in newspapers (3.27) fell into the "rarely" category. News items or features on television (3.51), newspaper ads (3.60), television ads (3.63), e-mail ads (3.80), and discussion groups (3.84) were more closely associated with the "never" category than the "rarely" category. Chat-rooms (4.00) "never" encouraged on-line shopping for this group.

\section{JOINT SPACE PERCEPTUAL MAPS}

Joint space perceptual maps were generated by using Multiple Correspondence Analysis (HOMALS) in SPSS. This was chosen because HOMALS provides a joint space perceptual map among the categorical variables that is easier to interpret than traditional chi square tables showing the interrelationships among the variables.

Table Seven

Multiple Correspondence Analysis Results

\begin{tabular}{|c|c|c|c|c|c|c|}
\hline Age & & Gender & & Education & & Income (Household) \\
\hline $18-24$ & 1 & Male & 2 & Less than High School & 1 & under 30,000 \\
\hline $25-34$ & 2 & Female & 1 & High School & 2 & $30-50,000$ \\
\hline $35-44$ & 3 & & & Some College/Tech & 3 & $50,-100,000$ \\
\hline $45-54$ & 4 & & & College Graduate & 4 & Over 100,000 \\
\hline 55-up & 5 & & & & & \\
\hline
\end{tabular}

\section{CLUSTERS AND DEMO- GRAPHICS}

The map representing the
clusters and the demographic
variables reveals that Cluster One
was more associated with younger
respondents having a household
income in the 30-50 thousand dollar range and are either high school graduates or have some colleges or technical school background. Cluster Two was associated with male college graduates between the ages of 25 and 44 having a household income of over $\$ 100,000$. Cluster Three was most closely associated with older (45-64 years old) consumers and was moderately associated with upper income respondents (it is in the same quadrant based on dimensions). 


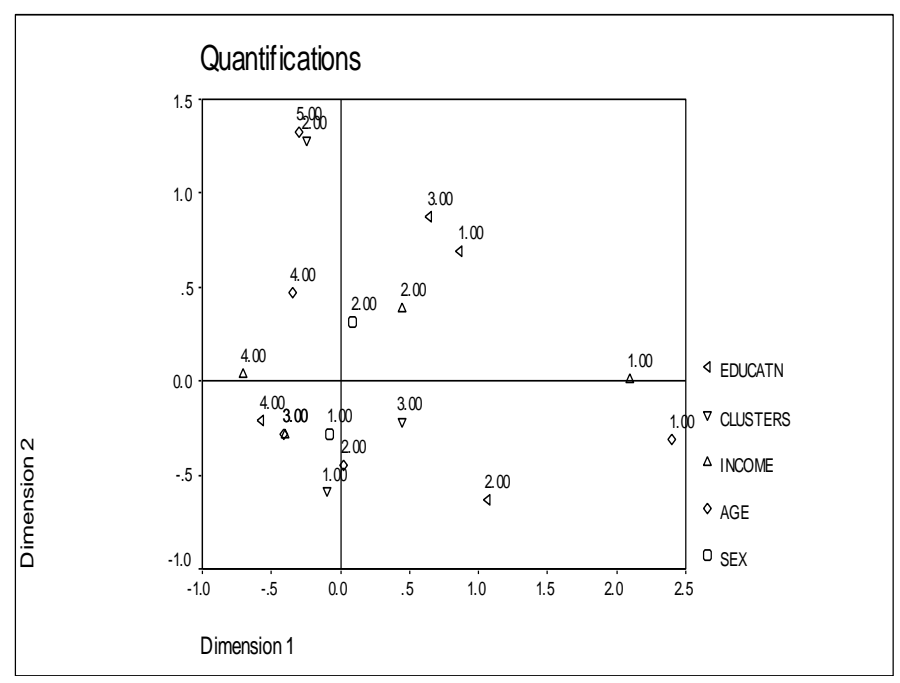

Table Eight

Multiple Correspondence Analysis Results

\begin{tabular}{|c|c|}
\hline \multicolumn{2}{|c|}{ The MCA map represents the following variables and the three cluster } \\
\hline \multicolumn{2}{|c|}{ How many orders have you placed on-line in the past year? (Order \#) } \\
\hline Less than 10 & 1 \\
\hline $11-20$ & 2 \\
\hline $21-50$ & 3 \\
\hline Over 50 & 4 \\
\hline \multicolumn{2}{|c|}{ How much money have you spent in on-line purchases? (Dollramt) } \\
\hline Less than $\$ 100$ & 1 \\
\hline$\$ 101-\$ 500$ & 2 \\
\hline$\$ 501-\$ 1000$ & 3 \\
\hline over $\$ 1000$ & 4 \\
\hline
\end{tabular}

\section{CLUSTERS AND SHOPPING}

Looking at the quadrants of the perceptual map, we see that Cluster One is associated with the larger dollar and order amounts, Cluster Two is associated with a smaller number of orders and smaller dollar amounts. Cluster Three did not have any close neighbors on the joint map.

\section{Message Differences}

To determine if there were differences in perceptions regarding the benefits and concerns of shopping on-line among the clusters, discriminant analysis was performed. The results indicate that there are significant differences among the clusters with regard to these variables. This indicates that different messages within the marketing communications mix are appropriate for the previously identified segments based on media consumption. 


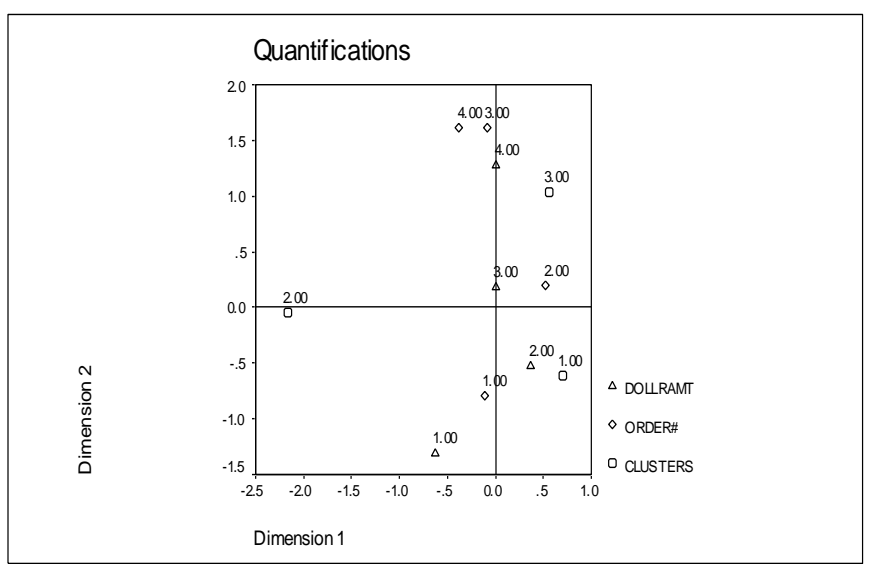

Table Nine

Concerns about on-line shopping

\begin{tabular}{|c|c|c|c|c|c|c|c|}
\hline \multirow[t]{2}{*}{ Item } & \multirow[t]{2}{*}{$\begin{array}{l}\text { Mean } \\
\text { CL1 }\end{array}$} & \multirow[t]{2}{*}{$\begin{array}{l}\text { Mean } \\
\text { CL2 }\end{array}$} & \multirow[t]{2}{*}{$\begin{array}{l}\text { Mean } \\
\text { CL3 }\end{array}$} & \multirow[t]{2}{*}{ Wilkes } & \multirow[t]{2}{*}{ Sig. } & \multicolumn{2}{|c|}{$\begin{array}{l}\text { Standardized } \\
\text { annonical } \\
\text { Coefficients }\end{array}$} \\
\hline & & & & & & F1 & $\mathrm{F} 2$ \\
\hline $\begin{array}{l}\text { Concern about using credit cards for } \\
\text { purchases }\end{array}$ & 1.53 & 1.93 & 1.68 & .974 & .017 & .318 & -.500 \\
\hline Delivery costs & 1.63 & 1.86 & 1.88 & .980 & .044 & .373 & .547 \\
\hline Inconvenience of returning items & 1.67 & 2.04 & 1.90 & 977 & .033 & .271 & -.192 \\
\hline Wait time to receive items ordered & 2.06 & 2.40 & 2.14 & 984 & 080 & .059 & -.676 \\
\hline Inability to see feel touch or try items & 2.10 & 2.42 & 2.51 & .973 & 015 & .349 & .637 \\
\hline May be required to pay extra taxes & 2.48 & 2.32 & 2.44 & .997 & 640 & -.469 & .256 \\
\hline $\begin{array}{l}\text { Need to write checks or money order } \\
\text { to send pavment }\end{array}$ & 2.60 & 2.96 & 2.93 & .983 & .074 & .415 & .101 \\
\hline
\end{tabular}

Wilks' Lambda

\begin{tabular}{|l|r|r|r|r|}
\hline Test of Function(s) & $\begin{array}{c}\text { Wilks' } \\
\text { Lambda }\end{array}$ & Chi-square & \multicolumn{1}{|c|}{ df } & \multicolumn{1}{c|}{ Sig. } \\
\hline 1 through 2 & .907 & 29.370 & 14 & .009 \\
2 & .977 & 7.001 & 6 & .321 \\
\hline
\end{tabular}

There were significant differences between the clusters regarding the benefits of Internet shopping. Both discriminant functions were significant. The first function is significant at the .001 level and the second is significant at the .1 level. There were univariate differences between the clusters on six of the eleven variables assessing the benefits of shopping on-line.

Differences were found in the following variables: Seeing a picture prior to purchase $(\mathrm{P}=.094)$ was most associated with Cluster One. Direct shipping $(\mathrm{P}=.031)$ was considered most important by Cluster Two. Internet shopping is a more efficient use of time $(\mathrm{P}=.002)$ was associated with Cluster Three. The ability to purchase items not found locally $(\mathrm{P}=.005)$ was associated with Cluster One, as was the ability to shop 24 hours a day $(\mathrm{P}=.006)$ and the availability of gift wrapping services $(\mathrm{P}=.015)$. 
Table Ten

Benefits of On-line Shopping

\begin{tabular}{|c|c|c|c|c|c|c|c|}
\hline \multirow{2}{*}{ Item } & \multirow{2}{*}{$\begin{array}{l}\text { Mean } \\
\text { CL1 }\end{array}$} & \multirow{2}{*}{$\begin{array}{l}\text { Mean } \\
\text { CL2 }\end{array}$} & \multirow{2}{*}{$\begin{array}{r}\text { Mean } \\
\text { CL3 }\end{array}$} & \multirow[b]{2}{*}{ Wilkes F. } & \multicolumn{3}{|c|}{$\begin{array}{l}\text { Standardized } \\
\text { annonical }\end{array}$} \\
\hline & & & & & & $\begin{array}{l}\text { Sig. } \\
\text { F1 }\end{array}$ & $\begin{array}{l}\text { Coefficients } \\
\text { F2 }\end{array}$ \\
\hline Seeing a picture prior to purchase $*$ & 1.87 & 2.11 & 2.02 & .985 & .094 & -.284 & .418 \\
\hline Direct shipping * & 2.15 & 2.28 & 1.91 & .978 & .031 & .408 & -.472 \\
\hline Free shipping $*$ & 2.16 & 2.43 & 2.19 & .986 & .118 & .182 & .005 \\
\hline Wider variety to choose from $*$ & 2.19 & 2.42 & 2.21 & .987 & .136 & .209 & .049 \\
\hline More efficient use of time $*$ & 2.27 & 2.61 & 2.07 & .959 & .002 & .614 & -.040 \\
\hline Sales or discounts available $*$ & 2.26 & 2.46 & 2.36 & .992 & .282 & -.065 & .096 \\
\hline $\begin{array}{l}\text { Ability to Purchase items not found } \\
\text { locally * }\end{array}$ & 2.26 & 2.70 & 2.33 & .965 & .005 & .143 & .420 \\
\hline Ability to shop 24 hours a day $*$ & 2.38 & 2.78 & 2.31 & .967 & .006 & .247 & .342 \\
\hline No interaction with salespeople $*$ & 3.26 & 3.31 & 3.16 & .998 & .730 & .019 & -.276 \\
\hline Free gift with purchase $*$ & 3.58 & 3.79 & 3.58 & .993 & .333 & .070 & .250 \\
\hline Gift wrapping services * & 3.79 & 3.98 & 4.22 & .973 & .015 & -.671 & .440 \\
\hline
\end{tabular}

\begin{tabular}{|c|c|c|c|c|}
\hline \multicolumn{5}{|c|}{ Wilks' Lambda } \\
\hline Test of Function(s) & $\begin{array}{c}\text { Wilks' } \\
\text { Lambda }\end{array}$ & Chi-square & df & Sig. \\
\hline 1 through 2 & .846 & 50.301 & 22 & .001 \\
\hline 2 & .942 & 17.886 & 10 & .057 \\
\hline
\end{tabular}

Differences also exist among the variables addressing the concerns regarding on-line shopping. The first function is significant at the .05 level, however the second was not significant. The univariate tests revealed significant differences on six of the seven variables.

There were differences among the clusters regarding the concerns of on-line shopping on the following variables. Concern about using credit cards for purchases $(\mathrm{P}=.017)$, delivery costs $(\mathrm{P}=.044)$, inconvenience of returning items $(\mathrm{P}=.033)$, wait time to receive items ordered $(\mathrm{P}=.080)$, inability to see feel touch or try items $(\mathrm{P}=.015)$, need to write checks or money orders to send payment $(\mathrm{P}=.074)$ were all variables were most strongly associated with Cluster One.

\section{IMPLICATIONS OF CLUSTER PROFILES}

There were three clearly defined segments based on the reported impact of the media in initiating on-line shopping. The first segment indicated that the recommendations of family and friends and searching the net through keyword searches are the only information sources that impact their shopping behavior occasionally. This group was most associated with having placed more orders on-line and also having spent larger amounts of money on-line. Demographically, this group is younger and has a household income of $\$ 35,000-\$ 50,000$. Educationally they have completed high school and have some college or technical school or have completed college.

This segment considered all of the variables addressing the concerns about on-line shopping as more important than the other segments. They also considered several benefits as more important that the other two segments. The benefits were the ability to see a picture prior to purchase, to have access to items not found locally, the ability to shop 24 hours a day; and the availability of gift wrapping services.

The second segment was the most influenced by the media. Seven information sources influenced their online shopping occasionally. These are, in order of importance: recommendations of friends and family, keyword searches, articles in magazines, articles in newspapers, magazine ads, news or features on television and television 
ads. This group was middle aged and had household incomes of over $\$ 100,000$. They tended to have spent less on online purchases than segment one and placed fewer orders on-line. Direct shipping was more important to this segment than the other segments.

The third segment represented the oldest consumers of the three segments and was not closely associated with a level of shopping or spending on the Internet. They did not indicate they were influenced by any of the media sources of information and only rarely influenced by the recommendation of friends and family along with articles in magazines and keyword searches. This segment indicated the benefit of Internet shopping being a more efficient use of time was more important to them than the other segments.

\section{RESULTING STRATEGY}

Based on these results, it was suggested to the e-tailer to focus its resources on creating positive WOM and PR. Since these were the most effective at stimulating on-line shopping. A very aggressive, targeted PR campaign was initiated and targeted niche magazines serving the e-tailer's niche. Feature stories were also generated for broadcast media. Advertising was used as a support media after the PR started a buzz within the target audience. On-line media, such as banner ads and e-mail were used after the public relations buzz created the positive WOM and generated e-tail store traffic. It was recommended that the flow to the web site be mapped (using cookies) and banners and reciprocal links be placed along the common paths.

The web page itself had an opt in e-mail program set up. After the e-tailer's opening, the media were again evaluated and the mix adjusted based on the CPI and ROI similar to the method suggested by Woodside.

The message strategies also differed across the segments. A core primary message was crafted and utilized for consistency. The secondary and supporting messages within the ads or PR placements were targeted at the first or second segment based on the media method being utilized.

\section{LIMITATIONS/FUTURE RESEARCH}

As with all studies, there are several limitations to this research. While the study demonstrates how to develop a data driven IMC campaign, the results can not be generalized across industries or even outside of the etailer's niche. The purpose was not to develop definitive segments for targeting, rather it was to demonstrate how customized IMC media and method mixes can be developed.

Another limitation of the study is the number of respondents in the data sample. Future studies should employ larger data sets. In this case, budgetary constraints precluded the collection of a larger sample size.

Additional studies are needed to explore how to compare the results of the PR and WOM with the advertising results and determine the increased impact this synergy creates. Research should focus on determining the appropriate measures to compare WOM and PR to be compared with advertising and what level reach and frequency with the combined methods are sufficient to generate the desired results for the e-tailer.

\section{CONTRIBUTIONS TO LITERATURE}

This paper makes several contributions to the literature. The results demonstrate that customizable IMC plans can be developed based on media consumption, with targeted media and message strategies flowing from the segments. The paper also demonstrates that media consumption can be used as a basis for segmentation. The segments differed not only in media consumption patterns but also regarding the perceptions of the benefits and concerns of internet shopping. This information was utilized to craft messages within the media. Finally, the research also presents an overview of a technique to develop the initial message and media mix in an IMC campaign. 


\section{CONCLUSION}

This paper has demonstrated that segmentation based on media consumption is a viable method to develop an integrated marketing communications campaign. The segments were not only robust and useful for developing media strategies but differences were also found between the segments regarding potential message content dealing with the benefits and concerns of internet shopping.

\section{REFERENCES}

1. Abe, M., (1997). “A Household-Level Advertising Exposure Model,” Journal of Marketing Research. 343 394-405.

2. Bond, G. \& I. Brace (1997). "Segmenting by attitudes to TV advertising - eye opener or blind alley?" Journal of the Market Research Society. 193 481-508.

3. Bond, J. \& R. Kirshenbaum (1998). Under the Radar an ADWEEK Book, John Wiley and Sons 605 Third Ave. New York NY 10158-0012.

4. $\quad$ Broadbent, S., J. Z. Spittler \& K. Lynch (1997). "Building Better TV Schedules: New Light from single source data." Journal of Advertising Research 37, 4 27-31.

5. Bruner, G. and A. Kumar (2000). "Web Commercials and Advertising Hierarchy of Effects Journal of Advertising Research 40 1/2 35-43.

6. Chaturvedi, A., J.D. Carroll, P. Green \& J.A.Rotondo (1997). "A feature-Based Approach to Market Segmentation Via Overlapping K-Centroids Clustering.” Journal of Marketing Research .34, 3, 370-377.

7. Davis B., W. Donnelly, (1996) Media Planning: Strategy and Imagination, Prentice Hall Upper Saddle River $\mathrm{NJ}$

8. $\quad$ Erwin E. (2000) “A new media-mix strategy,” Advertising Age vol 71 iss 9 10-13.

9. $\quad$ Gibson, L. (1996). "What can one TV exposure do?” Journal of Advertising Research 36 29-19.

10. Hair, J. R. Jr., R. Anderson, R. Tatham and W. Black (1998).Multivariate Data Analysis $5^{\text {th }}$ ed. Prentice Hall Upper Saddle River NJ

11. Harris, T. (1994) PR gets personal Direct Marketing vol 56 iss 12 29-33.

12. Harvey, B. (1997). "The expanded ARF model: Bridge to the accountable advertising future," Journal of Advertising Research .37, 2, 11-21.

13. Hoeffler, S. E. (2003). "Notion of ad overspending lessons with integrated communications" Marketing News. 37, 34, 30.

14. Hutton, J. G (1996) "Integrated marketing Communications and the Evolution of Marketing Thought" Journal of Business Research 37 155-162.

15. Javalgi, R., T. Whipple, M. McManamon (1992). "Hospital Image: A Correspondence Analysis Approach" Journal of Health Care Marketing $12434-41$

16. Kim, C. R. (2002). "Identifying viewer segments for television programs." Journal of Advertising Research $42151-66$.

17. Korgaonkar, P., R. Silverblatt and B. O'Leary (2001). "Web advertising and Hispanics." Journal of Consumer Marketing 182 134-152.

18. Leckenby, J. and J. Hong (1998). "Using Reach/Frequency for Web Media Planning.” Journal of Advertising Research 38 1 7-20

19. Lloyd, D. and K. J. Clancy (1991) "CPMs versus CPMIs: Implications for media planning” Journal of Advertising Research $31434-45$.

20. $\quad$ Masterson, P. (1999) The Wearout phenomenon Marketing Research 113 26-31.

21. Moriarity S. (1994). "PR and IMC: The benefits of integration" Public Relations Quarterly vol 39 iss 3 3845.

22. Naik, P. and K. Raman (2003) "Understanding the impact of synergy in multimedia communications" Journal of Marketing Research 40, 4375.

23. Puth, G., P. Mostert and M. Ewing (1999). "Consumer perceptions of mentioned product and brand attributes in Magazine advertising" Journal of Product and Brand Management 81 38-49. 
24. Rossiter J. R. and Percy 1. (1997). Advertising Communications and Promotions Management McGraw Hill New York NY.Schaffer, C. and P. E.Greene. (1998). "Cluster-based market segmentation: some further comparisons of alternative approaches." Journal of the Market Research Society 402 155-163.

25. Schultz, D. and P. Kitchen (1997) Integrated Marketing Communications in U.S. Advertising Agencies: An exploratory study. Journal of Advertising Research 7-18.

26. Schultz, Don (2003) Outdated approach to planning needs revamping. Marketing News 36 23 6-7.

27. Schultz, D. E., S. Tannenbaum and R. Lauterborn (1993) Integrated Marketing Communications: Putting it together and making it work Lincolnwood IL NTC Business Books.

28. Sissors, J. and L. Bumba (1996) Advertising Media Planning NTC Business Books Lincolnwood IL $5^{\text {th }}$ ed.

29. Smith, E. and P. C. Neijens (2000) "Segmentation based on affinity for advertising" Journal of Advertising Research 404 35-43.

30. Taylor, J. (1993) How to develop a successful advertising plan Chicago NTC Business Books

31. Wansink, B. and S. B. Park (2000) "Methods and measures that profile heavy users" Journal of Advertising Research 404 61-72.

32. Woodside, A. G. and P.K. Soni (1990) "Performance Analysis of Advertising in Competing Media Vehicles" Journal of Advertising Research 301 53-66.

33. Woodside A. G. (1994). "Modeling linkage-advertising: Going beyond better media comparisons." Journal of Advertising Research july aug 22-31

34. Zeff, R. and B. Aronson (1999) Advertising on the Internet $2^{\text {nd }}$ ed. Wiley Computer Publishing 605 Third Ave. New York NY 